\title{
UM RECURSO HISTORICO PARA ESTUDOS INICIAIS DE TRIGONOMETRIA: APRESENTANDO O TEODOLITO
}

\section{A HISTORICAL RESOURCE FOR INITIAL TRIGONOMETRY STUDIES: PRESENTING THEODOLITE}

\author{
Maria Helena de Andrade ${ }^{1}$ \\ Instituto Federal de Educação, Ciência e Tecnologia do Ceará - IFCE \\ Rannyelly Rodrigues de Oliveira ${ }^{2}$ \\ Instituto Federal de Educação, Ciência e Tecnologia do Ceará - IFCE \\ Ana Carolina Costa Pereira ${ }^{3}$ \\ Universidade Estadual do Ceará- UECE
}

\begin{abstract}
Resumo
O artigo "Um Recurso Histórico para Estudos Iniciais de Trigonometria: Apresentando o Teodolito" discorre sobre uma estratégia de ensino vivenciada no interior da sala de aula, laboratório e a escola de forma autônoma pelos educandos do nono ano de uma escola da rede municipal de ensino em Fortaleza. Uma vez que, o intuito é abordar a História da Matemática no processo de construção do conhecimento matemático de forma autônoma e relacioná-la ao conteúdo ora visto em sala de aula. A princípio, foi escolhida uma réplica do teodolito primitivo como forma de incentivá-los a prática da pesquisa e assim tornar as aulas de Matemática significantes e atrativas no processo de construção do conhecimento matemático. Esse artefato despertou a curiosidade dos educandos desencadeando uma pesquisa para conhecer, construir e realizar medições com o instrumento matemático. No entanto, o processo se deu de forma empírica, ou seja, a metodologia utilizada foi a Engenharia Didática com suas quatro fases: análise prévia ou preliminar, análise a priori, experimentação, análise a posteriori e validação. Os registros das atividades ocorreram através de observações, fotos e anotações. Os alunos se entusiasmaram e efetivaram as atividades propostas com dinamismo e empolgação. Relacionaram o teodolito com o cálculo da tangente. Todavia, sentiram dificuldade em colocar no papel as medidas para posteriormente efetuar os cálculos. Dessa forma, a prática em sala de aula utilizando o teodolito oportunizou uma opção de mudança no ato de aprender interagindo o conteúdo com o artefato matemático desde sua origem até sua utilização nos dias atuais em sala de aula.
\end{abstract}

Palavras-chave: Teodolito; construção do conhecimento; relações no triângulo retângulo.

\footnotetext{
${ }^{1}$ E-mail: helenaeducadoramat@gmail.com.

${ }^{2}$ E-mail: nanny-rockstar@hotmail.com.

${ }^{3}$ E-mail: carolinapereira@uece.br
} 


\begin{abstract}
The article "A Historical Resource for Initial Studies of Trigonometry: Introducing the Theodolite" discusses a strategy of teaching lived inside the classroom, laboratory and the school autonomously by the students of the ninth year of a school in the municipal school network in Fortaleza. Since, the intention is to approach the History of Mathematics in the process of constructing mathematical knowledge autonomously and to relate it to the content now seen in the classroom. At first, a replica of the primitive theodolite was chosen as a way to encourage them to practice research and thus make Mathematics classes significant and attractive in the process of constructing mathematical knowledge. This artifact aroused the curiosity of the students, triggering a research to know, construct and perform measurements with the mathematical instrument. However, the process was empirical, that is, the methodology used was Didactic Engineering with its four phases: preliminary or preliminary analysis, a priori analysis, experimentation, a posteriori analysis and validation. Records of activities occurred through observations, photos, and notes. The students were enthusiastic and carried out the proposed activities with dynamism and excitement. They related the theodolite to the calculation of the tangent. However, they found it difficult to put the measurements on the paper for later calculations. In this way, the classroom practice using theodolite provided an option to change the act of learning by interacting the content with the mathematical artifact from its origin to its use in the current days in the classroom.
\end{abstract}

Keywords: Theodolite; construction of knowledge; relationships in the right triangle.

\title{
Introdução
}

A Matemática é essencial à vida, uma vez que, ela "[...] se constitui de uma linguagem revestida por elementos significantes que procuram expressar os significados evidenciados a cada relação que estruturamos para comunicar nossas ideias” (MENDES, 2009, p. 21). No entanto, os alunos da Educação Básica a veem como algo pronto e acabado cheio de fórmulas e símbolos desassociado do cotidiano do educando, deixandoos desinteressados e consequentemente desmotivados. Apresentando muitas dificuldades.

Diante dessa realidade, como introduzir a História da Matemática no estudo do conteúdo relações do triângulo retângulo numa turma de nono ano do Ensino Fundamental? Para responder a indagação foi utilizada como metodologia a Engenharia Didática numa sequência de ensino em sala de aula por intermédio da curiosidade da turma após verem um instrumento matemático, o teodolito primitivo.

Dessa forma, com o intuito de abordar a História da Matemática no processo de construção do conhecimento do educando de forma autônoma, relacionando-a ao conteúdo visto em sala de aula foi escolhido, a princípio, o teodolito primitivo para incentivá-los a prática da pesquisa. Seguida da construção e utilização do teodolito no estudo das relações no triângulo retângulo. 


\section{ENREDO HISTÓRICO DO TEODOLITO}

O teodolito é um instrumento matemático antigo, atualizado e modernizando, o qual vem sendo aprimorado ao longo dos anos e utilizando em várias áreas do conhecimento. No entanto, não é frequente seu uso nas aulas de Matemática do nono ano do Ensino Fundamental. Provavelmente, pelo fato de não ser comum os professores de Matemática considerar a História da Matemática (HM) como apoio no incentivo da construção do conhecimento matemático, sendo a conexão entre a abstração e a realidade. Visto que, a aula poderá ficar mais atraente, incitando assim, o educando a conjecturar.

Contudo, a HM não é uma simples contação de história. Na visão de Saito (2015) a HM não está pronta e acabada pelo contrário ela é reinterpretada e reescrita de tempos em tempos. Logo, é um rico instrumento para utilização em sala de aula. Daí, a necessidade do professor de Matemática da Educação Básica conhecê-la e usá-la quando estiver estudando com a turma os conteúdos de ângulos ou relações no triângulo retângulo por intermédio do teodolito.

Esse instrumento matemático foi referenciado pela primeira vez (consta ser até o presente momento) com o nome de theodolitus em um livro raro denominado de $A$ Geometrical Practical Named Pantometria (figura 1) conhecido como Pantometria da autoria de Leonard Cavalheiro Digges, publicado na Inglaterra na primeira metade do século XVI por seu filho Thomas Digges.

Figura 1 - Frontispício de Pantometria.

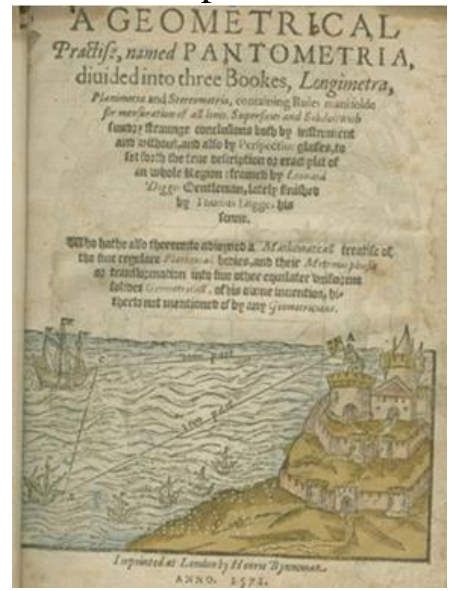

Fonte: Digges - 1571. Disponível no site:

http:/quod.lib.umich.edu/e/eebo/A20458.0001.001?rgn=main:view=fulltext.. Acesso em: 15 jan 2018 
Nessa época, o teodolito (figura 2) era um instrumento usado por navegadores e topógrafos ingleses para medir ângulos horizontais e verticais do céu e da topografia em graus graduados em torno de seu perímetro. Para efetuar a medição os profissionais o posicionavam em cima de uma mesa por ser objeto plano, mas poderia ser outro objeto, com o intuito de medir com precisão e adquirir firmeza ao ser manobrado, sempre apontando ao norte.

Figura 2 - Teodolito primitivo de Leonard Digges.

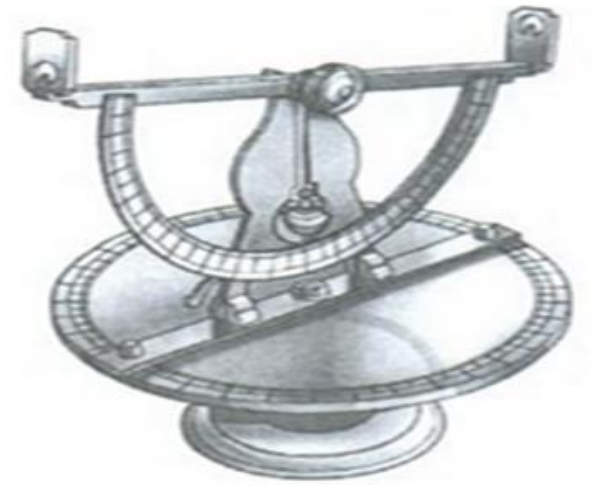

Fonte: Santos (2015, p. 62).

Do ponto de vista de Ferreira (2000, p.668) o teodolito é um "instrumento óptico para medir com precisão ângulos horizontais e verticais”. Além disso, se pode dizer que atualmente o teodolito é um artefato usado para efetuar medição de terras, distâncias pequenas e incalculáveis. Prova disto é o teodolito que fez medições, inclusive de distâncias com curvas para construir Brasília (figura 3). Ou seja, é um instrumento matemático útil na Engenharia.

Figura 3 - Teodolito usado na fundação de Brasília.

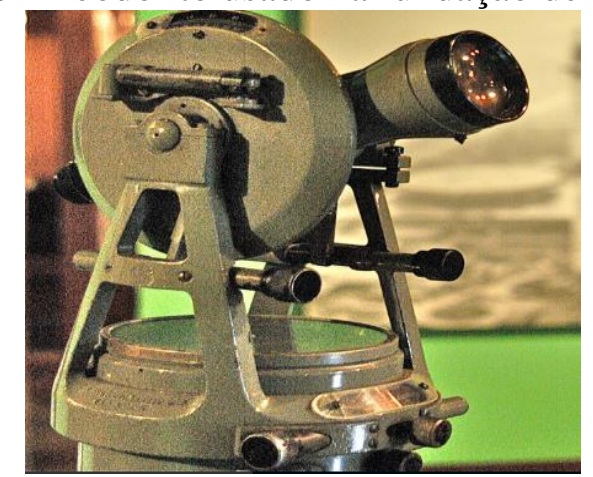

Fonte: https://upload.wikimedia.org.

Dessa forma, o teodolito a partir do instante que passou a medir vários tipos de distâncias, inclusive de um observador até o topo de uma árvore frondosa e grande, por 
exemplo, está usando a Trigonometria. Este por sua vez, poderá ser levado pelo professor à sala de aula com o propósito de conduzir o educando a enxergar o processo de construção do conhecimento matemático. Daí se percebe a conectividade das formas existentes na sociedade com o conteúdo "relação no triângulo retângulo", mostrando assim que o teodolito e ensino da Matemática estão relacionados intrinsicamente. Agora uma das maneiras em que o vínculo acontece é que será vislumbrado na seção $a$ posteriori.

\section{METODOLOGIA}

O caminho percorrido para utilização do instrumento matemático (theodolitus) em sala de aula e relacioná-lo com o objeto de estudo (relações no triângulo retângulo) foi por intermédio de um processo empírico denominado de Engenharia Didática (ED). Do ponto de vista de Brum e Schumacher a ED enquanto metodologia "caracteriza-se como produto didático que envolve plano de ensino, criação de materiais didáticos e esquema experimental, baseado nas realizações didáticas em sala, ou seja, sobre concepção, realização, observação e avaliação" (2013, p. 63-64).

Desse modo, o esquema experimental aconteceu em quatro fases: análise prévia, análise a priori, experimentação, análise a posteriori e validação. Na análise prévia a professora de Matemática pesquisou e pensou antecipadamente de forma sequencial as estratégias que seriam usadas durante a atividade. Para isso conversou com outros professores sobre a dificuldade dos alunos em compreender as relações trigonométricas no triângulo retângulo. Após a conversa foi concluído ser senso comum entre os professores que os alunos possuem dificuldade para internalizar o objeto de estudo. Este por sua vez, enxerga as relações como pura aplicação de fórmulas.

O contexto favoreceu a condução de uma busca com abordagem diferenciada do assunto. Afinal, o professor deve "[...] propor ao estudante uma situação de aprendizagem para que elabore seus conhecimentos como resposta pessoal a uma pergunta, e os faça funcionar ou os modifique como resposta às exigências do meio e não a um desejo do professor" (BROUSSEAU, 1996b, p.49). Assim, o levantamento realizado evidenciou o teodolito como instrumento de medida que pode ser usado no conteúdo relações no triângulo retângulo.

Mas como fazer isso? Geralmente, o papel do professor de Matemática é oferecer ao educando um conjunto de sequências de ensino que o encaminhe a autonomia do saber 
e, portanto, a efetivação da aprendizagem. Dessa forma, a atuação ativa do aprendiz durante o processo de aprendizagem precisa ser valorizada por intermédio da pesquisa para proporcionar significado ao objeto em estudo.

Assim, a professora realizou uma pesquisa e providenciou uma réplica simples (figura 4) do teodolito primitivo e levou-o a sala de aula para incitar os questionamentos dos 37 estudantes do nono ano de uma determinada escola da rede municipal de ensino situada na periferia de Fortaleza. A partir dos questionamentos é construída a sequência didática através da análise a priori, a qual favorece a comunicação em sala.

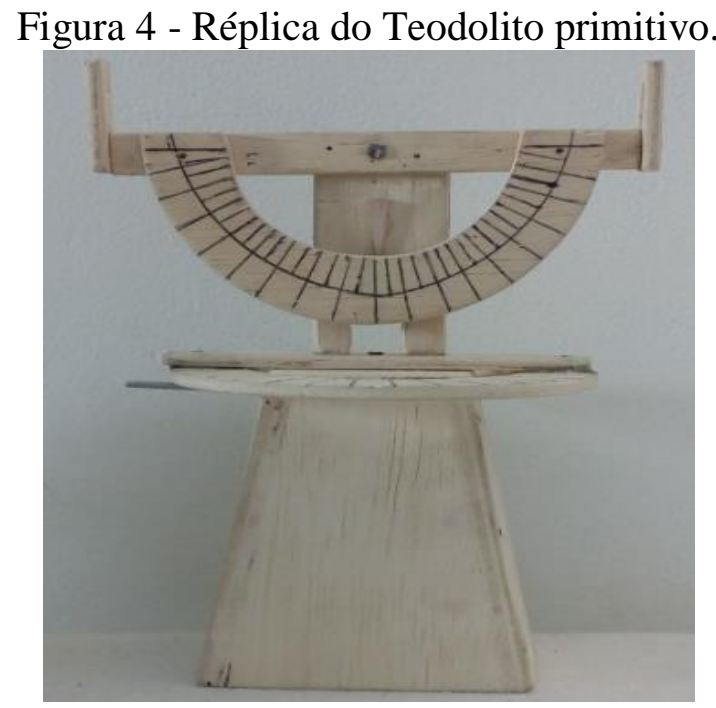

Fonte: Acervo dos autores.

Quando os alunos viram o teodolito primitivo deram início à enxurrada de perguntas, conforme a professora havia imaginado. Foi solicitado ao líder da sala que anotasse no quadro branco todas as perguntas, as quais em suma foram: o que é isso? Como funciona? Quem fez? Para que serve? De posse das perguntas a turma foi organizada em duplas (figura 5) para efetuar a pesquisa no laboratório da escola denominado de LABMAT. Salienta-se que o capítulo referente às relações no triângulo retângulo fora explicado anteriormente.

Figura 5 - alunos pesquisando. 


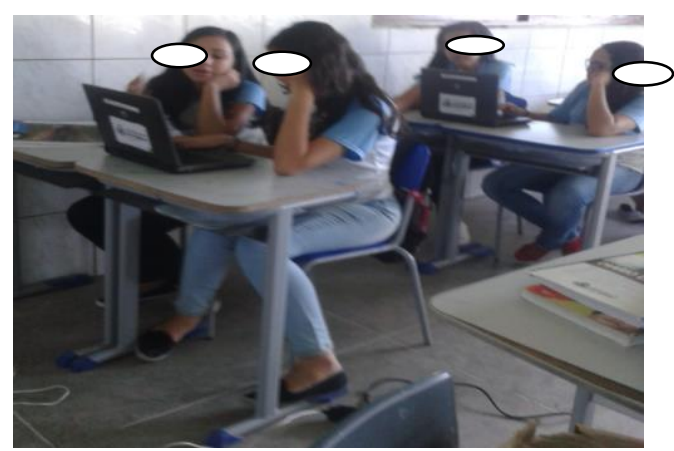

Fonte: Acervo dos autores.

A tarefa daquele dia era de descoberta. Isto é, a dupla realizava a pesquisa com o roteiro das indagações em três sites distintos para obter informações que pudessem levalos a respondê-las com o propósito de satisfazer as curiosidades. Foi explicado que pesquisar não é abrir no primeiro site que fale sobre o assunto e copiar tudo não. Uma pesquisa requer leitura e análise. Concluída a tarefa retornaram a sala de aula. Em seguida, construíram um relatório individual respondendo aos questionamentos citados.

$\mathrm{Na}$ aula seguinte a professora solicitou a leitura individual de alguns relatórios e intencionalmente fez alguns comentários do tipo: quem abordou primeiro o teodolito primitivo foi Sisson em 1835 ou Digges 1571? Por que afirmam que foi Digges? O que é o teodolito? Onde encontrá-lo? Como construí-lo? Na última indagação ficaram calados. Então retornaram ao laboratório para pesquisar e em comunicação com seu par evidenciar a resposta (figura 6).

Figura 6 - tutorial de construção do teodolito caseiro.

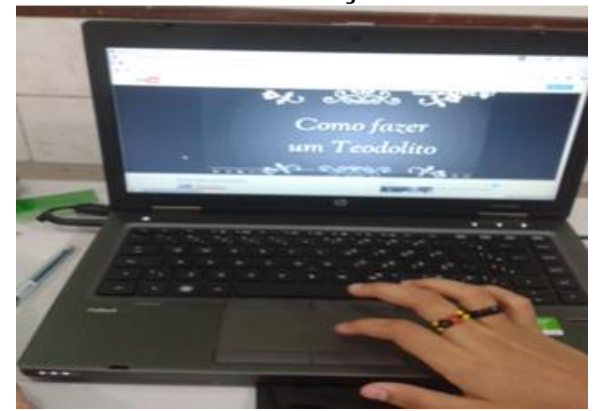

Fonte: Acervo dos autores.

Retornaram do LABMAT empolgados pedindo para explicar e depois construílo. E assim foi feito. As duplas voluntárias explicitaram o processo de construção. E ficou pactuado que na aula seguinte cada dupla iria construir seu teodolito caseiro. Indo, então para a etapa da experimentação. 
Chegou o dia esperado. Para realização dessa atividade a turma estava $100 \%$ presente. Juntaram as mesas, cada dupla organizou seu material. Iniciou-se o processo de construção. A figura 7 evidencia três teodolitos construídos. Os alunos queriam terminar logo porque o objetivo deles era aprender a medir com o teodolito. Após a construção cada dupla falou da sua experiência de "cientista". Todavia, foi observado durante o processo que nenhuma dupla desfez ou desdenhou do trabalho do outro.

Figura 7 - teodolito construído pelos alunos.

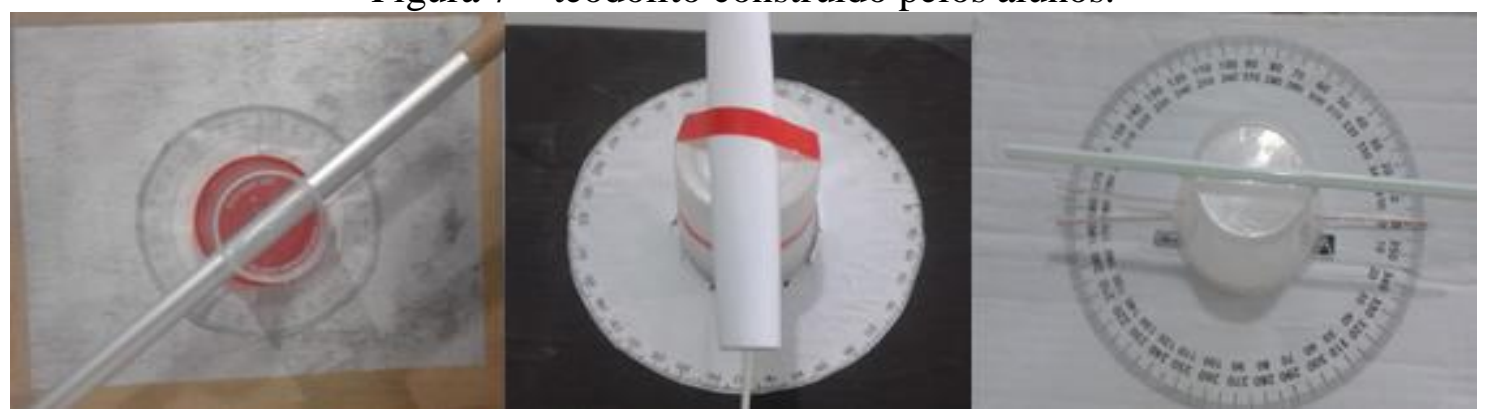

Fonte: Elaborado pelos autores.

$\mathrm{Na}$ aula seguinte houve a resolução de questões do livro didático Vontade de Saber Matemática referente ao conteúdo relações trigonométrica no triângulo retângulo para responderem questões do tipo "Questão 30. No momento do dia em que os raios do Sol estão inclinados $45^{\circ}$ em relação ao solo, o mastro no pátio de uma escola projeta uma sombra de 4,35 m. Qual a altura desse mastro?” (SOUZA; PATARO, 2015, p. 187)

Dando continuidade à etapa de experimentação, os alunos foram em campo, ou seja, as duplas ficaram espalhadas por toda a escola efetuando as etapas de medições e com o teodolito na medição de distâncias e ângulos, conforme figura 8, 9 e 10 .

Figura 8 - Etapa um de medição com o teodolito.

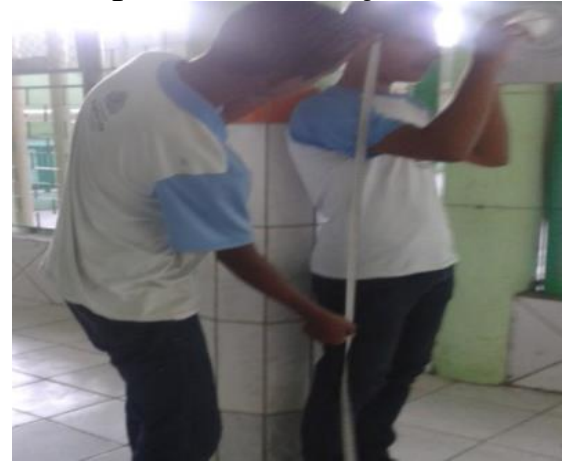

Fonte: Acervo dos autores.

Figura 9 - Etapa dois de medição com o teodolito. 


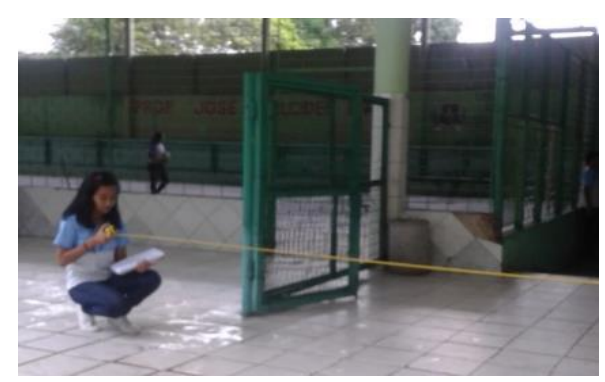

Fonte: Acervo dos autores.

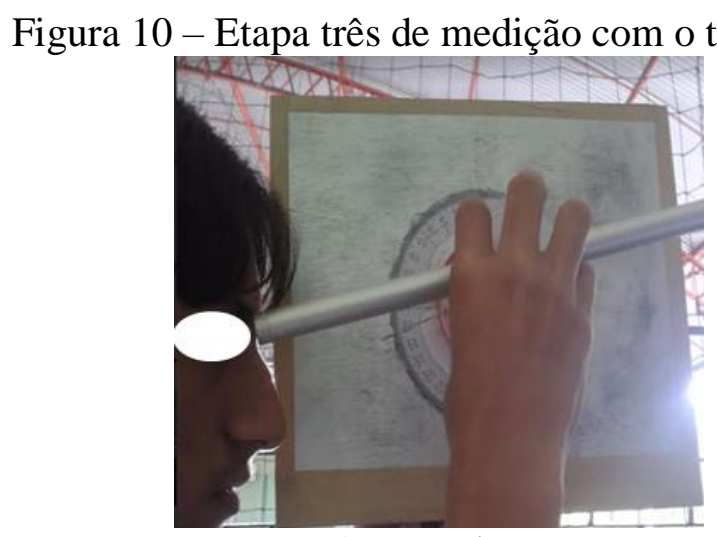

Fonte: Acervo dos autores.

As variáveis didáticas envolvidas nessa atividade foram: as medições de ângulo e distância, noção de tangente que permite o cálculo com as medições colhidas e a solução apresentada pelas duplas no cálculo da tangente relacionando a teoria com a prática. Evidencia-se que segundo Gálvez (1996) variáveis didáticas são aquelas para as quais as escolhas de valores provocam modificações nas estratégias de resolução de problemas.

Essa atividade de conhecer o teodolito, aprender a construí-lo e efetuar medidas utilizando-o teve vários objetivos, tais como: incentivar os alunos na construção do conhecimento matemático; registrar as produções dos alunos com a mínima intervenção da professora; relacionar um instrumento matemático com o cotidiano e verificar se os estudantes sabiam efetuar as medições e posteriormente calcular a tangente.

Por fim, a etapa 4 (análise a posteriori e validação) se acentuou na construção dos conhecimentos matemáticos dos estudantes na sala de aula, no LABMAT e por toda a escola. Os dados evidenciados ocorreram através de observações, fotos e anotações. Portanto, esta etapa se caracteriza pela confrontação com a análise a priori, permitindo a interpretação dos resultados.

Logo, é possível salientar as contribuições do teodolito para o estudo das relações no triângulo retângulo, em particular as relações trigonométricas, permitindo a validação do objetivo da pesquisa. 
Conforme previsto na análise preliminar, os aprendizes com a curiosidade aguçada realizaram uma pesquisa em sites com o intuito de responder as indagações relatadas. Responderam que o teodolito foi construído por Leonard Digges em 1571. Definiram o teodolito como sendo um instrumento matemático que serve para medir ângulos e grandes distâncias e, portanto, muito útil no cálculo de tangente. A turma respondeu bem quanto ao processo de construção e medição com o teodolito.

A princípio, os alunos no ato da medição tiveram dificuldade em resolver a questão do livro antes da experimentação. Não apresentaram nenhuma dificuldade em medir com o teodolito. No entanto, apresentaram dificuldade no momento de anotar as medidas para efetuar o cálculo da tangente.

Contudo, a indagação como relacionar o teodolito ao conteúdo relações no triângulo retângulo fora respondida, uma vez que, os estudantes detectavam através do teodolito o ângulo e anotava. Em seguida anotava a medida do olho do observador ao piso como também a medida do observador ao local determinado (rede da quadra, portão da escola, rampa, entre outros). Ambos fazendo uso da trena. E efetuava as operações necessárias.

Além do mais, ao término dos cálculos concluíram que se tratava da tangente do ângulo determinado pelo teodolito, fazendo assim a relação. Essa prática facilitou os cálculos com as atividades existentes no livro didático, visto que, eles faziam associações do tipo: Ah! Esse ângulo é igual ao encontrado com o teodolito, olha aí esse valor parece à medida de mim até o local escolhido na hora que tava usando o teodolito. Conduzindoos a terem autonomia do saber no processo de construção do conhecimento.

\section{RESULTADOS}

De acordo com a confrontação dos dados, entre análise prévia, análise a priori e análise a posteriori, foi possível observar que os educandos, de modo geral, iniciaram o processo de investigação através da curiosidade existente ao visualizar a réplica do teodolito primitivo, levando-os a construírem seu conhecimento matemático com a interferência mínima possível da professora. E a perceberem a relação do teodolito com o conteúdo relações no triângulo retângulo no momento que efetuaram os cálculos. 
Contudo, mesmo estando todos empolgados e admirados com a forma de construção do conhecimento foi detectado que tiveram sucesso nas medições de distância e noção de tangente, mas apresentaram dificuldade em anotações com medidas.

Dessa forma, a prática em sala de aula utilizando o teodolito não só auxiliaram os educandos no processo de construção do conhecimento de forma autônoma como também ofereceram ainda, a oportunidade de uma opção de mudança no ato de aprender interagindo o conteúdo com um artefato matemático desde sua origem.

\section{Referências}

Brousseau, Guy. Os diferentes papéis do professor. In: PARRA, Cecília; SAIZ, Irma (org). Didática da Matemática: Reflexões Psicológicas. Porto Alegre: Artes Médicas, 1996b. Cap. 4, p. 48-72.

BRUM, Wanderley Pivatto; SCHUHMACHER, Elcio. A Engenharia Didática como campo Metodológico para o Planejamento de aula de Matemática: análise de uma experiência didática para o estudo de geometria esférica. Jornal Internacional de estudos em Educação Matemática, 2013, v. 6 (2), pp. 60-84.

FERREIRA, Aurélio Buarque de Holanda. Minidicionário Século XXI: O Minidicionário de Língua Portuguesa. Coordenação de edição: Margarida dos Anjos et al. $4^{\mathrm{a}}$ ed; Rio de Janeiro: Nova Fronteira, 2000. 790 p.

GÁLVEZ, Grecia. A Didática da Matemática. In: PARRA, Cecília; SAIZ, Irma (org). Didática da Matemática: Reflexões Psicológicas. Porto Alegre: Artes Médicas, 1996. Cap. 2, p. 26-35.

MENDES, Iran Abreu. Investigação Histórica no Ensino da Matemática. 1 ed. Rio de Janeiro: Ciência Moderna Ltda, 2009. 258 p.

SAITO, F. História da Matemática e suas (re)construções contextuais. São Paulo: Livraria da Física, 2015. 259 p.

SANTOS, Luis Anderson de Moráis. Utilização de material concreto no ensino de matemática: uma experiência com o teodolito caseiro no ensino de Trigonometria. Dissertação apresentada ao Mestrado Profissional de Matemática em rede nacional PROFMAT, da Universidade Federal de Rondônia. Porto Velho, 2015. 88p.

SOUZA, Joamir; PATARO, Patricia Moreno. Vontade de Saber Matemática. 3. ed. São Paulo: FTD, 2015, 448 p. 